\title{
Morphological Characterization of Bipolaris oryzae Causing Brown Spot Disease of Rice
}

\author{
P. Valarmathi* and D. Ladhalakshmi \\ Department of Plant Pathology, ICAR-Indian Institute of Rice Research (IIRR), \\ Hyderabad-500 030, Telangana, India \\ *Corresponding author
}

\section{A B S T R A C T}

Keywords

Rice, Brown spot, Bipolaris oryzae, Colony morphology

Article Info

Accepted: 04 January 2018 Available Online: 10 February 2018
Brown spot disease caused by Bipolaris oryzae results in the yield loss of paddy in the recent years. In the present study, isolates were collected from nine rice growing states of India. Based on colony morphology and growth pattern, the 17 isolates of $B$. oryzae were characterized and formed four groups. These were (Group I) black with fluffy growth, (Group II) grey with fluffy growth and white spots, (Group III) grey with fluffy growth and (Group IV) grey with suppressed growth. Further the morphological characterization was studied on different media and spectral values for all isolates.

\section{Introduction}

Rice is one of the most important cereal crops and feeds more than one third of the world's population (Burgos et al., 2013). Rice is susceptible to several leaf spot diseases including blast and brown spot, which cause significant yield losses across the globe. During 1942, Great Bengal Famine occurred wherein the yield loss was upto $90 \%$ in epiphytotic form at leaf spot phase (Ghose et al., 1960). Being the disease reported in 1919, extensive research has been carried due to which the disease was controlled. In the recent years, because of the climate change and cultivation practices, disease was found to be severe in dry/ direct seeded rice in the states of
Bihar, Chhattisgarh, Madhya Pradesh, Odisha, Assam, Jharkhand and West Bengal. It especially occurs in the environment where scarce water resource combined with nutritional imbalance particularly lack of nitrogen and often referred to as "Poor man's disease", (Baranwal et al., 2013).

The pathogen attacks the crop from seedling to milky stage. The symptoms appear as minute spots on the coleoptile, leaf blade, leaf sheath and glume, being most prominent on leaf blades and glumes. On leaves, typical spots are brown in colour with grey or whitish centre resembling sesame seed with typical yellow halo over the spot (Sunder et al., 2005). Conidia are 5-10 septate with the oldest 
conidium towards base. Typically conidia are slightly curved and widest at the middle. The optimum temperature for growth and conidial germination has been found to be $27-30^{\circ} \mathrm{C}$ and $25-30^{\circ} \mathrm{C}$ respectively $(\mathrm{Ou}, 1985)$. Conidia are formed between $5-38^{\circ} \mathrm{C}$, optimum being $25^{\circ} \mathrm{C}$ (Ou, 1985; Vinay Kumari et al., 1997). Both light and dark periods were required for sporulation of $B$. oryzae. However, it was stimulated by near-ultra violet light and inhibited by blue light (Ou, 1985). Morphopathological and molecular characterization of B. oryzae has been carried out for fifty isolates in India (Kumar et al., 2011). Diversity and pathogenicity of the rice brown spot pathogen were investigated earlier by many workers using morphological characteristics as well as genetic fingerprint analysis in India as well as in other rice growing countries (Ouedraogo et al., 2004; Motlagh and Kaviani, 2008; Kamal and Mia, 2009; Motlagh and Anvari, 2010; Burgoss et al., 2013, Archana et al., 2014, Kandan et al., 2014 and Nazari et al., 2015). Morphological, molecular characterization and grouping of 27 isolates of Bipolaris oryzae from India were carried out by Singh et al., 2016. Morpho-molecular diversity for 116 isolates of Bipolaris oryzae from different rice growing areas of India was studied by Kumar et al., 2016. The present paper emphasised on the morphological characterization of Bipolaris oryzae amended with different culture media.

\section{Materials and Methods}

\section{Isolation of Bipolaris oryzae}

A total of 17 samples of rice leaves infected with Bipolaris oryzae were collected from Andhra Pradesh, Chattisgarh, Haryana, Himachal Pradesh, Jammu \& Kashmir, Punjab, Telangana, Uttar Pradesh and West Bengal of India. The fungus, B. oryzae was isolated from single discrete lesion from the infected leaf tissue followed by incubation for
2-3 days and further mycelial growth was sub cultured. The purified cultures were maintained on potato dextrose agar (PDA) slants at $4^{\circ} \mathrm{C}$. The colony morphology with respect to colony colour and growth pattern was observed 5 days after inoculation among all the 17 isolates of $B$. oryzae on PDA medium.

\section{Colony morphology in different media}

The colony morphology for all the seventeen isolates were carried out in different media viz., Rice extract with potato dextrose agar, Rice extract with oat meal agar, Rice polish agar and Malt extract agar. The radial growth of the fungus was measured 5 days after inoculation for all the 17 isolates on different media. The statistical analysis was carried out with the software OPSTAT developed by CCSHAU, Haryana.

\section{Spectral values of isolates}

All the 17 isolates of $B$. oryzae were grown on PDA medium at $25^{\circ} \mathrm{C}$. After 5 days of growth, the plates were photographed using a Nikon camera (20.1mp). The spectral RGB (Red, Green, Blue) values for each isolate was calculated using Adobe Photoshop (Chand et al., 2008).

\section{Results and Discussion}

\section{Morphological characterization of $\boldsymbol{B}$. oryzae isolates}

The pattern of growth of $B$. oryzae among isolates showed significant differences with the range of means varying from $3.6 \mathrm{~cm}$ (BO $13 \& \mathrm{BO} 15)$ to $2.1 \mathrm{~cm}$ (BO 9) with five days after inoculation on PDA (Plate 1a, $1 \mathrm{~b}$ and Table 1). Based on colony morphology and growth pattern, the 17 isolates of $B$. oryzae were characterized and formed four groups. These were (Group I) black with fluffy 
growth, (Group II) grey with fluffy growth and white spots, (Group III) grey with fluffy growth and (Group IV) grey with suppressed growth (Plate 2). Isolates $\mathrm{BO} 2,4,8,15$ and 16 were under group II wherein isolates $\mathrm{BO}$ $12,13 \& 14$ were under group I. Of all the isolates, those of Group II and III had the highest frequency $(29.4 \%)$ in the population, whereas Group I had the lowest frequency (17.6\%) (Table 2). All the seventeen isolates were maintained as pure cultures on PDA slant. One of the major difficulties in isolation of Bipolaris is the common contaminant of Curvularia spp, as colonies of both the fungus look similar and identification is only possible through examination of spores. Enhancement of sporulation seems difficult in the pathogen and hence only three isolates were found to produce conidial spores.

In the present study, isolates of $B$. oryzae were grouped into four categories based on the colony morphology and growth pattern. Earlier Kumar et al., (2011) grouped fifty isolates of $B$. oryzae into four categories. Similarly Singh et al., (2016) grouped twenty seven isolates of the pathogen into five categories. The fifth category with pink fluffy growth colony morphology was not observed in our isolates and isolates studied by Kumar et al., (2011).

The first group with black colony characteristics was also observed in the isolates of $B$. oryzae in rice reported by Kumar et al., (2011), Singh et al., (2016) and B. sorokiniana in wheat by Kumar, 2003 and Aggarwal et al., (2011). On the basis of colony morphology and growth pattern on PDA, 116 isolates were grouped into 8 groups viz., black with suppressed growth, black with cottony growth, black with fluffy growth, grey with suppressed growth, grey with cottony growth, grey with fluffy growth, grey and white mix with cottony growth and white with cottony growth. Majority of the isolates
$(62.93 \%)$ were black followed by grey (33.62\%) among the Bipolaris oryzae isolates (Kumar et al., 2016).

\section{Conidial characterization}

Conidia were usually curved, fusoid or obclavate, occasionally almost cylindrical, pale to mid golden brown, 5 to 6 septate with hillum.

The conidia exhibited bipolar germination pattern and hence named the pathogen as Bipolaris. The size of BO conidia were measured with three microscopic fields and average were calculated (Plate 3 ).

The length and breadth of BO 12 was $113.32 \mathrm{x}$ $27.41 \mu \mathrm{m}$, BO 13 was $56.89 \times 14.27 \mu \mathrm{m}$ and BO 14 was $63.42 \times 13.75 \mu \mathrm{m}$ (Table 3).

Spore dimensions of all $\mathrm{BO}$ isolates varied from $90.34 \mu \mathrm{m}$ to $137.48 \mu \mathrm{m}$ in length while width varied from 14.10 to $23.51 \mu \mathrm{m}$ was observed by Kumar et al., 2016.

\section{Morphological characterization of $\boldsymbol{B}$. oryzae isolates on different media}

The pattern of growth of $B$. oryzae among isolates showed significant differences with the range of means varying from $3.0 \mathrm{~cm}$ (BO 11 and $\mathrm{BO} 13$ ) to $1.5 \mathrm{~cm}$ (BO $1 \&$ BO 5) with five days after inoculation on Rice extract+ Potato Dextrose Agar.

The pattern of growth of $B$. oryzae among isolates showed significant differences with the range of means varying from $3.0 \mathrm{~cm}$ (BO 13) to $1.5 \mathrm{~cm}$ (BO 14) with five days after inoculation on Rice extract+ Oat Meal Agar. The pattern of growth of $B$. oryzae among isolates showed significant differences with the range of means varying from $3.3 \mathrm{~cm}$ (BO 13) to $1.8 \mathrm{~cm}$ (BO 5) with five days after inoculation on Rice Polish Agar. 
Table.1 Radial growth of Biploaris oryzae isolates

\begin{tabular}{|c|c|c|c|c|c|}
\hline \multirow[t]{2}{*}{$\begin{array}{c}\text { S. } \\
\text { No }\end{array}$} & \multirow[t]{2}{*}{ Isolates } & \multirow[t]{2}{*}{ Place of collection } & \multicolumn{3}{|c|}{$\begin{array}{l}\text { Radial growth (in } \mathrm{cm} \text { ) } \\
5 \text { days after inoculation on PDA medium }\end{array}$} \\
\hline & & & R1 & R2 & Mean \\
\hline 1. & BO 1 & Ponnampet, Andhra Pradesh & 2.9 & 3.0 & 3.0 \\
\hline 2. & BO 2 & Bilaspur, Chattisgarh & 2.2 & 2.3 & 2.3 \\
\hline 3. & BO 3 & Jagadalpur, Chattisgarh & 2.5 & 2.4 & 2.5 \\
\hline 4. & BO 4 & Raipur, Chattisgarh & 3.0 & 3.9 & 3.0 \\
\hline 5. & BO 5 & Rewa, Chattisgarh & 2.5 & 2.6 & 2.6 \\
\hline 6. & BO 6 & Uchani, Haryana & 2.7 & 2.8 & 2.8 \\
\hline 7. & BO 7 & $\begin{array}{l}\text { Dhaula khan, Himachal } \\
\text { Pradesh }\end{array}$ & 2.3 & 2.3 & 2.3 \\
\hline 8. & BO 8 & Chatha, Jammu \& Kashmir & 3.4 & 3.2 & 3.3 \\
\hline 9. & BO 9 & Kapurthala, Punjab & 2.0 & 2.1 & 2.1 \\
\hline 10. & BO 10 & Luthiana, Punjab & 2.3 & 2.2 & 2.3 \\
\hline 11. & BO 11 & IIRR farm, Telangana & 2.3 & 2.2 & 2.3 \\
\hline 12. & BO 12 & ARI, Telangana & 2.8 & 3.0 & 2.9 \\
\hline 13. & BO 13 & IIRR farm, Telangana & 3.5 & 3.5 & 3.6 \\
\hline 14. & BO 14 & IIRR farm, Telangana & 3.4 & 3.3 & 3.4 \\
\hline 15. & BO 15 & Nagina, Uttar Pradesh & 3.5 & 3.6 & 3.6 \\
\hline 16. & BO 16 & Pantnagar, Uttar Pradesh & 3.3 & 3.0 & 3.2 \\
\hline \multirow[t]{3}{*}{17.} & BO 17 & Chinsurah, West Bengal & 2.6 & 2.7 & 2.7 \\
\hline & & & & CD* (0.05) & 0.381 \\
\hline & & & & SE (m) & 0.127 \\
\hline
\end{tabular}

Table.2 Bipolaris oryzae isolates group based on colony colour and growth pattern

\begin{tabular}{|l|l|l|l|l|}
\multirow{2}{*}{ Group } & Colony morphology & \multicolumn{2}{|c|}{ Population } & Isolates nos. \\
\cline { 3 - 5 } & & Number & Percentage (\%) & \\
\hline I & Black with fluffy growth & 3 & 17.6 & BO 12, 13 \& 14 \\
\hline II & Grey with fluffy growth \& white spots & 5 & 29.4 & BO 2, 4, 8, 15 \& 16 \\
\hline III & Grey with fluffy growth & 5 & 29.4 & BO 1, 6, 9,10 \& 17 \\
\hline IV & Grey with suppressed growth & 4 & 23.5 & BO 5, 7, 3 \& 11
\end{tabular}

Table.3 Size of B. oryzae conidia

\begin{tabular}{|l|l|l|l|}
\hline S. no & Isolates & Length $(\mu \mathrm{m})$ & Breadth $(\mu \mathrm{m})$ \\
\hline 1. & BO 12 & 113.32 & 27.41 \\
\hline 2. & BO 13 & 56.89 & 14.27 \\
\hline 3. & BO 14 & 63.42 & 13.75 \\
\hline
\end{tabular}


Table.4 Radial growth of $B$. oryzae isolates on different media

\begin{tabular}{|c|c|c|c|c|c|c|c|}
\hline \multirow{2}{*}{$\begin{array}{c}\text { S. } \\
\text { No } \\
\end{array}$} & \multirow[t]{2}{*}{ Isolates } & \multirow[t]{2}{*}{ Place of collection } & \multicolumn{5}{|c|}{ Radial growth (in $\mathrm{cm}$ ) 5 days after inoculation } \\
\hline & & & PDA & RE+PDA & RE+OMA & RPA & MEA \\
\hline 1. & BO 1 & Ponnampet, Andhra Pradesh & 3.0 & 1.5 & 1.8 & 2.3 & 1.5 \\
\hline 2. & BO 2 & Bilaspur, Chattisgarh & 2.3 & 2.5 & 2.3 & 2.3 & 1.8 \\
\hline 3. & BO 3 & Jagadalpur, Chattisgarh & 2.5 & 2.8 & 2.5 & 2.5 & 1.6 \\
\hline 4. & $\mathrm{BO} 4$ & Raipur, Chattisgarh & 3.0 & 2.5 & 2.3 & 2.5 & 1.5 \\
\hline 5. & BO 5 & Rewa, Chattisgarh & 2.6 & 1.5 & 2.0 & 1.8 & 2.0 \\
\hline 6. & BO 6 & Uchani, Haryana & 2.8 & 1.8 & 2.5 & 2.5 & 1.8 \\
\hline 7. & BO 7 & Dhaula khan, Himachal Pradesh & 2.3 & 2.5 & 2.5 & 2.0 & 1.8 \\
\hline 8. & BO 8 & Chatha, Jammu \& Kashmir & 3.3 & 2.5 & 2.8 & 3.0 & 2.0 \\
\hline 9. & BO 9 & Kapurthala, Punjab & 2.1 & 2.3 & 2.4 & 2.6 & 1.8 \\
\hline 10. & BO 10 & Luthiana, Punjab & 2.3 & 2.8 & 2.7 & 2.9 & 1.5 \\
\hline 11. & BO 11 & IIRR farm, Telangana & 2.3 & 3.0 & 2.0 & 2.2 & 2.0 \\
\hline 12. & BO 12 & ARI, Telangana & 2.9 & 2.0 & 1.8 & 2.0 & 1.8 \\
\hline 13. & BO 13 & IIRR farm, Telangana & 3.6 & 3.0 & 3.0 & 3.3 & 2.5 \\
\hline 14. & BO 14 & IIRR farm, Telangana & 3.4 & 2.5 & 1.5 & 2.5 & 2.0 \\
\hline 15. & BO 15 & Nagina, Uttar Pradesh & 3.6 & 2.3 & 2.0 & 2.0 & 1.8 \\
\hline 16. & BO 16 & Pantnagar, Uttar Pradesh & 3.2 & 2.8 & 2.3 & 2.8 & 2.0 \\
\hline 17. & BO 17 & Chinsurah, West Bengal & 2.7 & 2.3 & 2.0 & 2.0 & 1.5 \\
\hline & & $C D *(0.05)$ & 0.381 & 0.303 & 0.213 & 0.346 & 0.367 \\
\hline & & SE (m) & 0.127 & 0.101 & 0.071 & 0.115 & 0.122 \\
\hline
\end{tabular}

RE+PDA= Rice Extract+ Potato Dextrose Agar; RE+OMA= Rice Extract+ Oat Meal Agar; RPA=Rice Polish Agar; MEA=Malt Extract Agar

Table.5 Spectral values of B. oryzae isolates

\begin{tabular}{|l|l|l|c|c|c|c|}
\hline $\begin{array}{l}\text { S. } \\
\text { No }\end{array}$ & Isolates & Place of collection & Spectral values (5 days after inoculation) & Mean \\
\hline 1. & BO 1 & Ponnampet, Andhra Pradesh & 106 & 83 & 60 & $\mathbf{8 3}$ \\
\hline 2. & BO 2 & Bilaspur, Chattisgarh & 128 & 110 & 98 & $\mathbf{1 1 2}$ \\
\hline 3. & BO 3 & Jagadalpur, Chattisgarh & 125 & 110 & 97 & $\mathbf{1 1 1}$ \\
\hline 4. & BO 4 & Raipur, Chattisgarh & 132 & 114 & 95 & $\mathbf{1 1 4}$ \\
\hline 5. & BO 5 & Rewa, Chattisgarh & 83 & 65 & 49 & $\mathbf{6 6}$ \\
\hline 6. & BO 6 & Uchani, Haryana & 142 & 128 & 114 & $\mathbf{1 2 8}$ \\
\hline 7. & BO 7 & Dhaula khan, Himachal Pradesh & 123 & 106 & 88 & $\mathbf{1 0 6}$ \\
\hline 8. & BO 8 & Chatha, Jammu \& Kashmir & 131 & 115 & 98 & $\mathbf{1 1 5}$ \\
\hline 9. & BO 9 & Kapurthala, Punjab & 130 & 110 & 90 & $\mathbf{1 1 0}$ \\
\hline 10. & BO 10 & Luthiana, Punjab & 150 & 131 & 111 & $\mathbf{1 3 1}$ \\
\hline 11. & BO 11 & IIRR farm, Telangana & 126 & 105 & 85 & $\mathbf{1 0 5}$ \\
\hline 12. & BO 12 & ARI, Telangana & 134 & 116 & 101 & $\mathbf{1 1 7}$ \\
\hline 13. & BO 13 & IIRR farm, Telangana & 146 & 128 & 115 & $\mathbf{1 3 0}$ \\
\hline 14. & BO 14 & IIRR farm, Telangana & 179 & 155 & 134 & $\mathbf{1 5 6}$ \\
\hline 15. & BO 15 & Nagina, Uttar Pradesh & 100 & 78 & 53 & $\mathbf{7 7}$ \\
\hline 16. & BO 16 & Pantnagar, Uttar Pradesh & 113 & 92 & 67 & $\mathbf{9 1}$ \\
\hline 17. & BO 17 & Chinsurah, West Bengal & 120 & 95 & 76 & $\mathbf{9 7}$ \\
\hline
\end{tabular}


Plate.1a Variations in colony morphology on PDA among $B$. oryzae isolates

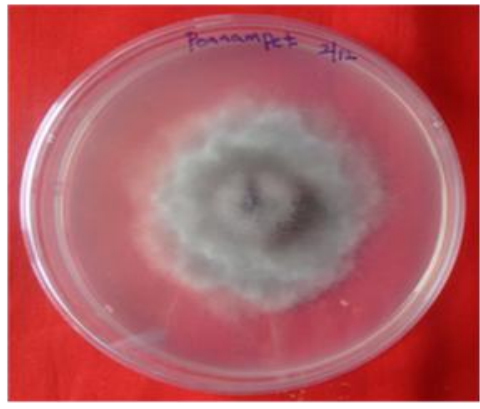

BO 1

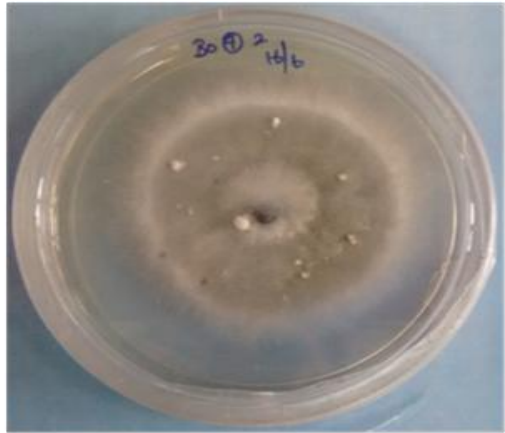

BO4

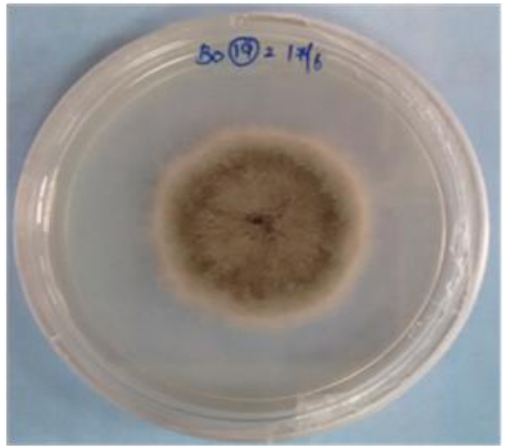

BO 7

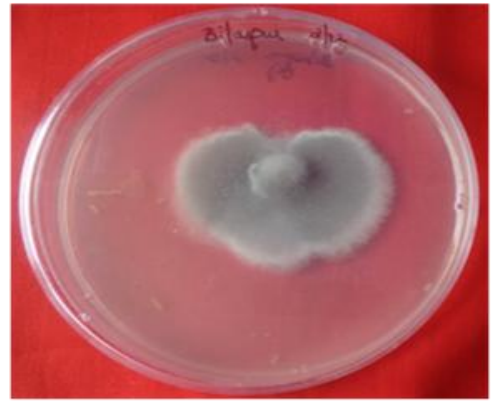

$\mathrm{BO} 2$

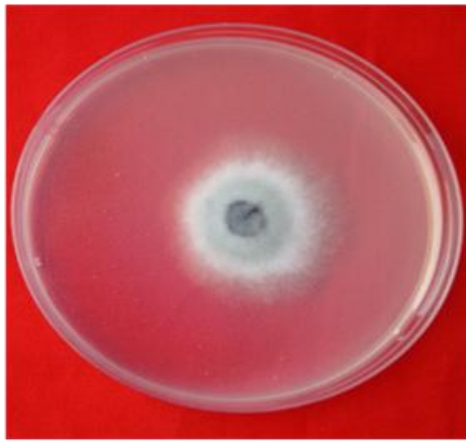

B05

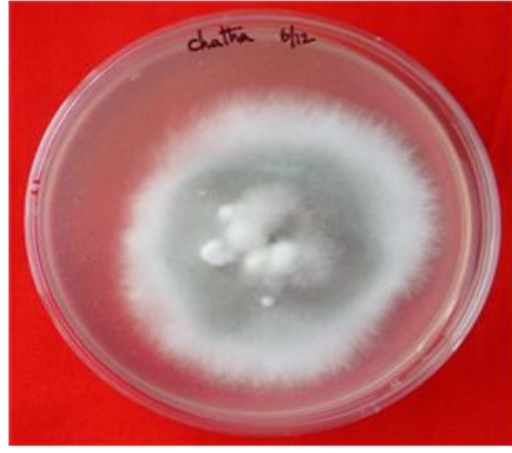

BO 8

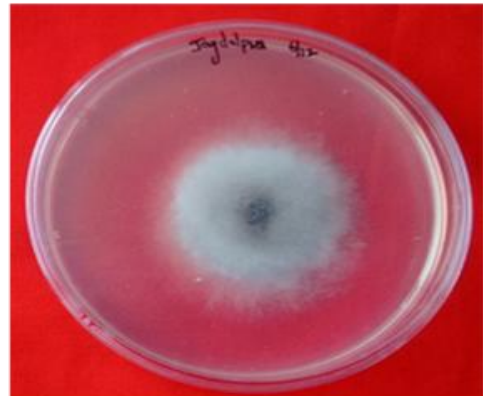

BO 3

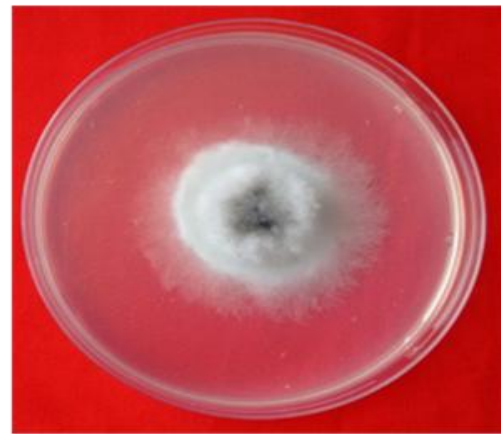

B06

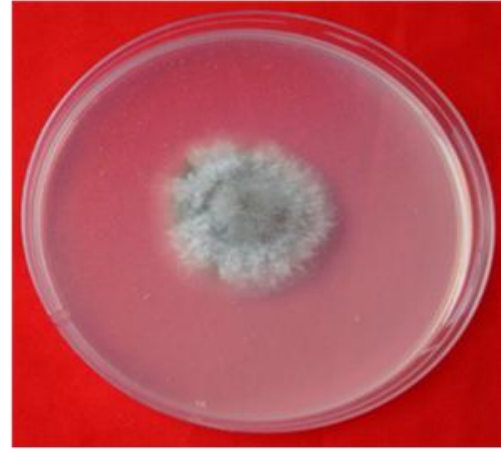

BO 9

Plate.1b Variations in colony morphology on PDA among B. oryzae isolates

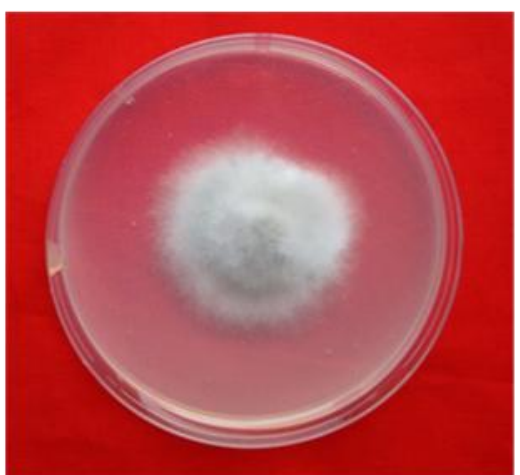

BO 10

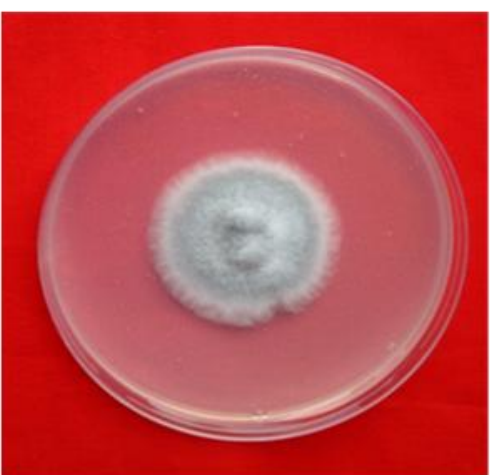

B0 11

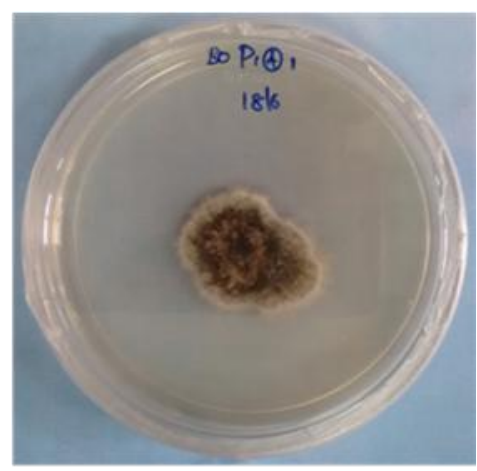

B0 12 


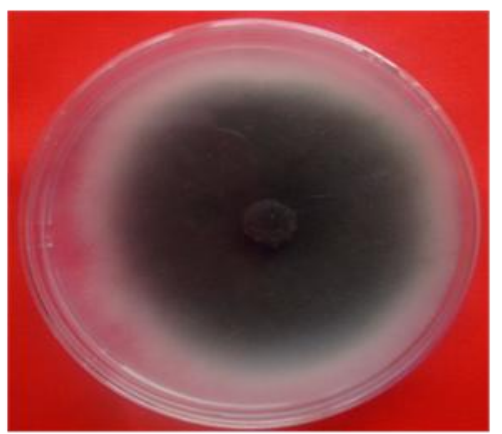

BO 13

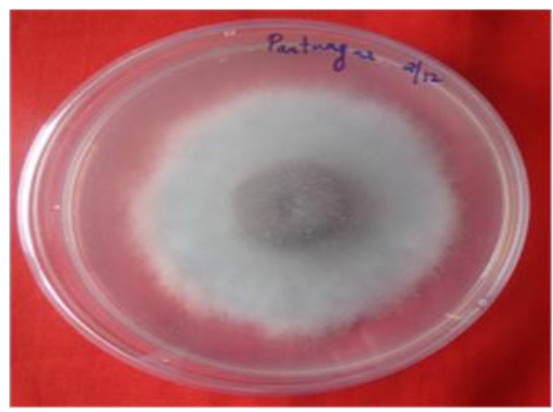

BO 16

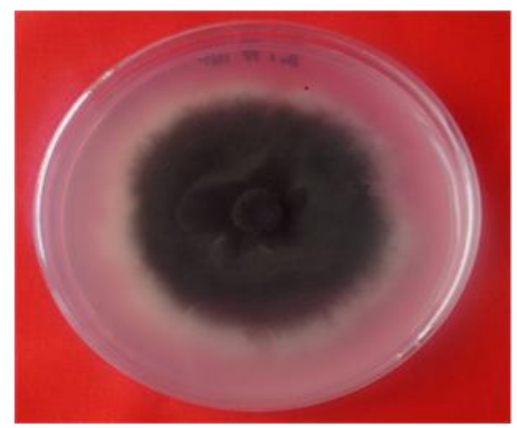

BO 14

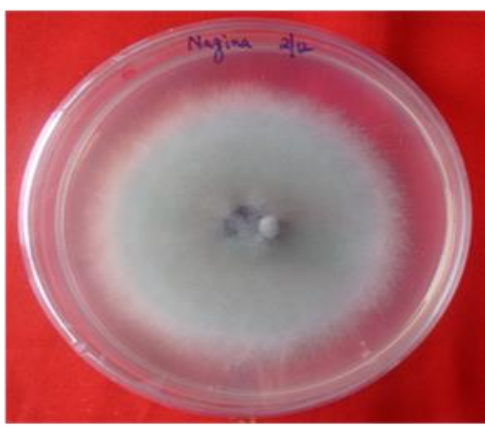

BO 15

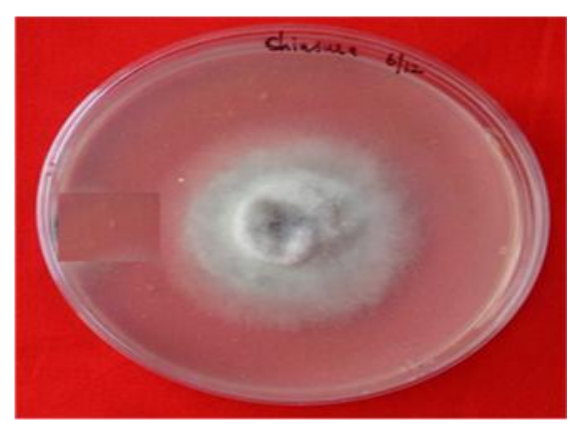

BO 17

Plate.2 Four different groups based on colony morphology of Bipolaris oryzae isolates

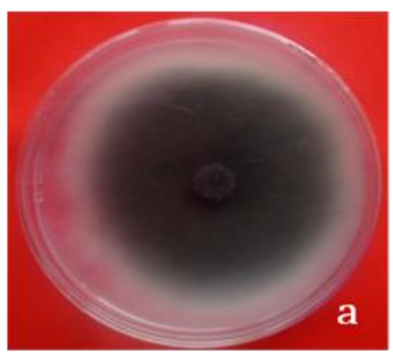

BO 14

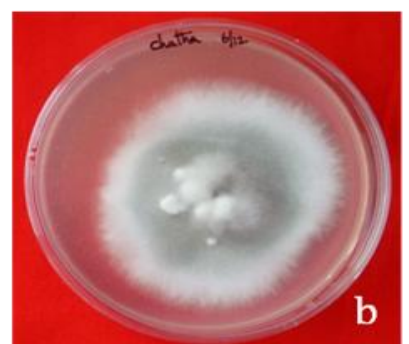

$\mathrm{BO} 8$

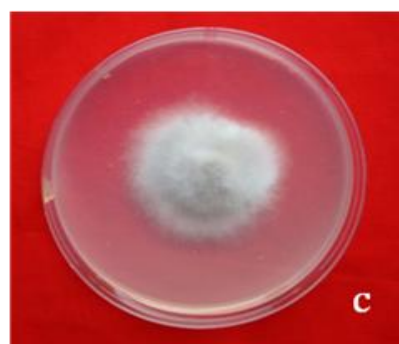

$\mathrm{BO} 10$

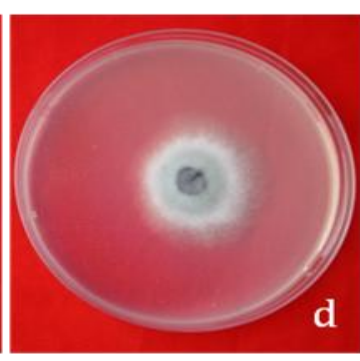

BO 5

Group I- Black with fluffy growth (a), Group II- Grey with fluffy growth \& white spots (b), Group III- Grey with fluffy growth (c) and Group IV- Grey with suppressed growth (d).

Plate.3 Conidia of B. oryzae with length and breadth $(\mu \mathrm{m})$

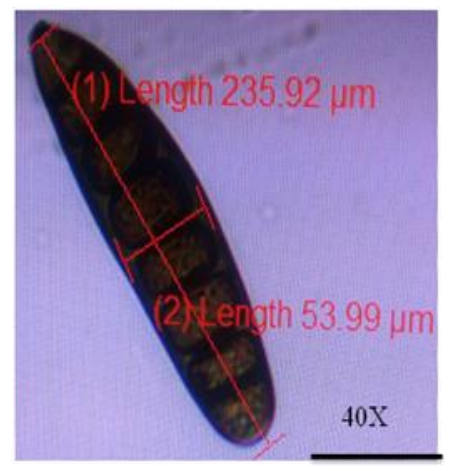

BO 12

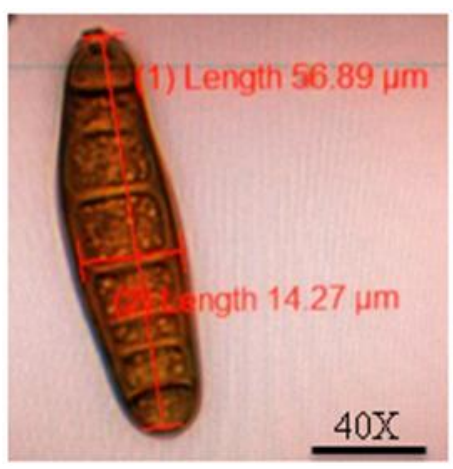

BO 13 


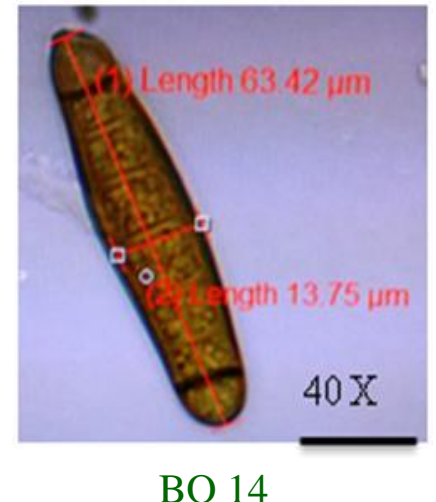

The pattern of growth of $B$. oryzae among isolates showed significant differences with the range of means varying from $2.5 \mathrm{~cm}$ (BO 13) to $1.4 \mathrm{~cm}$ (BO 4) with five days after inoculation on Malt Extract Agar (Table 4). Vinay Kumari et al., (1997) recorded maximum growth and sporulation of the fungus on corn meal agar medium followed by potato dextrose agar (PDA) and rice leaves agar wherein Arshad et al., 2013 noticed maximum growth of $B$. oryzae on malt extract and PDA after $96 \mathrm{~h}$ of incubation with optimum temperature at $28^{\circ} \mathrm{C}$. In our study all the four different media supported the growth of the pathogen wherein the Rice polish agar media enhances the sporulation of Bipolaris oryzae. Maximum sporulation was observed in the isolates which were black with suppressed growth and minimum sporulation was observed in the isolates which were grey and white mixed with cottony growth (Kumar et al., 2016). Similarly in our study the isolates with black fluffy growth were observed to enhance sporulation (BO 12, 13 and 14).

\section{Spectral values of isolates}

The mean spectral values for the isolates ranged from 66 (BO 5) to 156 (BO 14) (Table 5). Group I with black fluffy growth has higher RGB values. Isolates BO 14 with black fluffy growth had higher mean spectral value of 156. Isolate BO 5 with grey suppressed growth had less mean spectral value of 66 .

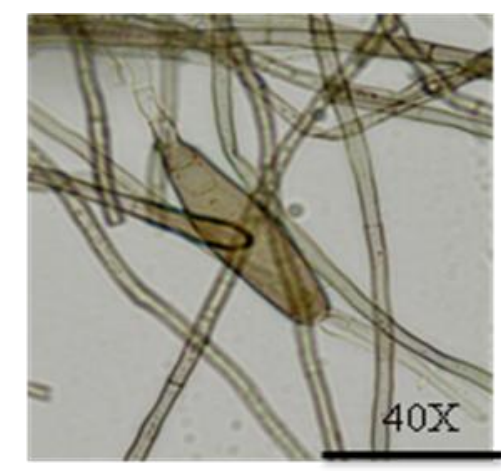

Bipolar germination of conidia

In the present study, the isolates of Bipolaris oryzae were characterized based on the colony colour and growth pattern and separated into four groups. Different media were used to study the morphology and its growth pattern. Further in future the research should focus on the enhancement of sporulation in the pathogen Bipolaris oryzae. It was observed that the pathogen Bipolaris oryzae isolated from seeds seems to produce spores. The sporulated isolates can be used to study its virulence in the susceptible rice cultivar and can be used further for screening the resistance source for the disease.

\section{Acknowledgement}

The authors are highly grateful to the Director, ICAR-Indian Institute of Rice Research, Hyderabad for the support and encouragement to carry out the work.

\section{References}

Aggarwal, R., Banerjee, S., Sharma, S., Gupta, S and Bashyal, B.M. 2011. Association of melanin content with conidiogenesis and virulence in Bipolaris Sorokiniana. J. Wheat Res., 3(1): 29-32

Archana, B., Kukandhuru, R.K. and Prakash, H.S. 2014. Genetic diversity and population structure among isolates of the brown spot fungus Bipolaris oryzae as revealed by inter-simple sequence 
repeats (ISSR). Afr. J. Biotechnol., 13(2): 238-44.

Arshad, H.M.I., Hussain, N., Ali, S., Khan, J.A., Saleem, K. and Babar, M.M. 2013. Behaviour of Bipolaris oryzae at different temperatures, culture media, fungicides and rice germplasm for resistance. Pak. J. Phytopathol., 25: 8490.

Baranwal, M.K., Kotasthane, A., Magculia, N., Mukherjee, P.K., Savary, S., Sharma, A.K., Singh, H.B., Singh, U.S., Sparks, A.H., Variar, M. and Zaidi, N. 2013. A review on crop losses, epidemiology and disease management of rice brown spot to identify research priorities and knowledge gaps. Eur. $J$. Plant Pathol, 136: 443-457.

Burgos, M. R. G., Katimbang, M. L. B., Dela Paz, M. A. G., Beligan, G. A., Goodwin, P. H. and Ona, I. P. 2013. Genotypic variability and aggressiveness of Bipolaris oryzae in the Philippines. Eur. J. Plant Pathol, 137: 415-429.

Chand, R., Sen, D., Prasad, K. D., Singh, A.K., Bashyal, B. M., Prasad, L. D. and Joshi, A. K. 2008. Screening for disease resistance in barley cultivars against Bipolaris sorokiniana using callus culture method. Indian J. Expt. Biol., 36: 249-253.

Ghose, R.L.M., Ghatge, M.B. and Subramanian, V. 1960. Rice in India (revised edn.), New Delhi, ICAR, 474 pp.

Kamal, M.M. and Mian, M.A.T. 2009. Diversity and pathogenicity of the rice brown spot pathogen in Bangladesh assessed by genetic fingerprint analysis. Bangladesh J. Biotechnol., 38: 119-25.

Kandan, A., Akhtar, J., Singh, B., Dixit, D., Chand, D., Roy, A., Rajkumar, S. and Agarwal, P.C. 2014. Molecular diversity of Bipolaris oryzae infecting Oryza sativa in India. Phytoparasitica,
43: 5- 14.

Kumar, A., Solanki, I.S., Akthar, J. and Gupta, V. 2016. Morpho-molecular diversity of Bipolaris oryzae causing brown spot of paddy. Indian J. Agri. Sci., 86 (5):615-20

Kumar, P., Anshu, V. and Kumar, S. 2011. Morpho-pathological and molecular characterization of Bipolaris oryzae in rice (Oryzae sativa). J. Phytopath., 159: 51-56.

Kumar, S. 2003. Variation in spot blotch spot pathogen and genetics of its resistance in wheat. Uttar Pradesh, India, Banaras Hindu University, PhD Thesis.

Motlagh, M. R.S. and Anvari, M. 2010. Genetic variation in a population of Bipolaris oryzae based on RAPD-PCR in North of Iran. Afr. J. Biotechnol., 9: 5800- 4.

Motlagh, M.R.S. and Kaviani, B. 2008. Characterization of new Bipolaris spp: the causal agent of rice brown spot disease in the North of Iran. Int. J. Agri. Biol., 10: 638-42.

Nazari, S., Mohamad, J-N., Khalil-Berdi, F., Vahid, K. and Alireza, A. 2015. Bipolaris species associated with rice plant: pathogenicity and genetic diversity of Bipolaris oryzae using repPCR in Mazandaran province of Iran. $J$. Crop Protection, 4: 497-508.

Ou, S.H. 1985. Rice Diseases 2nd edn. CMI, Kew, England, 370 pp.

Ouedraogo, I., Correll, J.C., Boza, E.J., Cartwright, R.D., Lee, F.N. and Sankara, P. 2004. Pathogenic, molecular and genetic diversity among Bipolaris, Drechslera, and Exserohilum species on rice. (In) Norman Rice Research Studies, RJ, Meullenet JF, Moldenhauer K A K, Wells BR (Eds.) pp11Q 9 AAES Research Series 529, Fayetteville, AR, USA.

Singh, K., Valarmathi, P., Sharma, S., Bashyal, B. M., Gurjar, M.S. and 
Aggarwal, R. 2016. Association of melanin content with pathogenicity and virulence in Bipolaris oryzae. Res. J. Biotech., 11(9): 37-42.

Sunder, S., Singh, R., Dodan, D.S. and Mehla, D.S. 2005. Effect of different nitrogen levels on brown spot (Drechslera oryzae) of rice and its management through host resistance and fungicides. Pl. Dis. Res., 20: 111-114.

Vinay Kumari, Jariwala, S. and Rai, B. 1997. Effect of physicochemical factors on growth of Drechslera oryzae. J. Mycopathol. Res., 35: 131-136.

\section{How to cite this article:}

Valarmathi, P. and Ladhalakshmi, D. 2018. Morphological Characterization of Bipolaris oryzae Causing Brown Spot Disease of Rice. Int.J.Curr.Microbiol.App.Sci. 7(02): 161-170. doi: https://doi.org/10.20546/ijcmas.2018.702.021 